\title{
PENGARUH MODEL PROBLEM BASED LEARNING TERHADAP HASIL BELAJAR IPS PADA SISWA KELAS IV SDI BAJAWA KECAMATAN BAJAWA KABUPATEN NGADA
}

\author{
Maria Patrisia Wau \\ STKIP Citra Bakti, NTT \\ Mariapatrisiawau@gmail.com
}

\begin{abstract}
Abstrak
Penelitian ini bertujuan untuk mengetahui perbedaan hasil belajar IPS antara siswa yang belajar menggunakan model Problem Based Learning dengan siswa yang belajar dengan menggunakan model pembelajaran konvensional pada siswa kelas IV SDI Bajawa. Penelitian ini merupakan penelitian eksperimen semu dengan rancangan penelitian Posttest Only Control Group Design. Populasi penelitian ini adalah siswa SDI Bajawa. Sampel penelitian ini adalah semua siswa kelas IV SDI Bajawa dengan kelas IV A sebagai kelompok eksperimen yang berjumlah 21 orang dan siswa kelas IV B sebagai kelompok kontrol yang berjumlah 20 orang. Data yang dikumpul dalam penelitian ini adalah hasil belajar IPS. Hasil belajar IPS dikumpulkan melalui tes objektif yang terdiri dari 20 butir soal. Data dianalisis dengan menggunakan statistik Inferensial dengan uji-t untuk menguji hipotesis penelitian. Dari perhitungan uji-t diperoleh thitung $=15,02$. Karena $\mathrm{n} 1 \neq \mathrm{n} 2$ dan homogen maka t-tabel dengan $\mathrm{db}=\mathrm{n} 1+\mathrm{n} 2-2=39$ dengan taraf signifikansi $5 \%$ $(\alpha=0,05)$ adalah 2,042. Ternyata t-hitung $=15,02>\mathrm{t}$-tabel $=2,042$, sehingga Ho ditolak dan $\mathrm{H}_{1}$ diterima. Ini berarti terdapat perbedaan yang signifikan hasil belajar IPS antara siswa yang belajar dengan menggunakan model Problem Based Learning dengan siswa yang belajar dengan menggunakan model pembelajaran konvensional. Dari rata-rata hitung diketahui bahwa rata-rata hitung kelompok Eksperimen lebih tinggi dari kelompok Kontrol $(66,40>56,9)$. Dengan demikian disimpulkan bahwa model Problem Based Learning berpengaruh terhadap hasil belajar IPS.
\end{abstract}

Kata-kata kunci : Hasil Belajar IPS, Model Problem Based Learning

\begin{abstract}
This study aimed at investigating whether or not there was a significant difference on sosial studies learning achievement between students who were treated by problem based learning and those who were treated by conventional technique. This study focused on fourth graders and took place in SDI Bajawa. This present study is an experimental study by using posttest only control group design. The population in this study was all four grade students in SDI Bajawa. From the sampling, there were 21 students from class IVA who were selected as the experimental group and 20 students from IVB as the control group. The data were gained through achievement test on social studies subject. A multiple choice test was administered consisting of 20 questions. The data were then analyzed inferentially through ttest to test the hypothesis in this study. From the t-test, it was gained that tobs $=15.02$. Since $n 1 \neq n 2$ yet homogeneous, thus the table with $\mathrm{df}=\mathrm{n} 1+\mathrm{n} 2-2=39$ with $5 \%$ of significance level $(\alpha=0.05)$ is 2.042 . The result of the aforementioned calculation shows that the $\mathrm{t}_{\mathrm{obs}}=15.02>\mathrm{t}_{\mathrm{table}}=2.042$, thus Ho is rejected and Ha is accepted. This means there is a significant difference between students who were treated by using problem based learning and those with conventional technique. From the average score of both groups, it was revealed that the experimental group got a higher score (66.40 $>$ 56.9) than the control group. Thus, it was concluded that problem based learning has a significant effect toward the learning achievement on social studies subject.
\end{abstract}

Keywords: Social Studies Learning Achievement, Problem Based Learning

\section{Pendahuluan}

Undang-undang Nomor 20/2003 menegaskan bahwa penyelenggaraan pendidikan pada Sekolah Dasar (SD) bertujuan memberikan bekal kepada siswa untuk hidup bermasyarakat, berbangsa, dan bernegara dalam konteks masyarakat yang berkeadaban berdasarkan nilai dan moral Pancasila serta dapat melanjutkan pendidikan ke jenjang yang lebih tinggi. Salah satu komponen untuk mencapai tujuan tersebut adalah melalui Ilmu Pengetahuan Sosial dalam bentuk mata pelajaran IPS terpadu untuk SD. 
Dalam Kurikulum 2006, mata pelajaran IPS disebutkan sebagai salah satu mata pelajaran yang diberikan mulai dari SD/MI sampai SMP/MTs. Mata pelajaran IPS mengkaji seperangkat peristiwa, fakta, konsep, dan generalisasi yang berkaitan dengan isu sosial. Pada jenjang SD/MI, mata pelajaran IPS memuat materi Geografi, Sejarah, Sosiologi, dan Ekonomi. Melalui mata pelajaran IPS, peserta didik disiapkan dan diarahkan agar mampu menjadi warga negara Indonesia yang demokratis dan bertanggung jawab, serta warga dunia yang cinta damai.

IPS memiliki tujuan untuk mengembangkan pengetahuan, sikap, dan keterampilan sosial dalam bentuk konsep dan pengalaman belajar yang dipilih atau diorganisasikan dalam rangka kajian IPS. Berkaitan dengan tujuan IPS, Martorella (1994: 7) menyatakan bahwa: The Social Studies are selected information and modes of investigation from the social sciences, selected information from any area that relates directly to an undestanding of individuals, groups, and societies and applications of the selected information to citizenship education.

Ilmu Pengetahuan Sosial merupakan informasi terpilih dan cara-cara investigasi dari ilmu-ilmu sosial, informasi dipilih dari berbagai tempat yang berhubungan langsung terhadap pemahaman individu, kelompok dan masyarakat dan penerapan dari informasi yang dipilih untuk maksud mendidik warga negara yang baik. Dari pengertian tersebut dapat dipahami bahwa mata pelajaran IPS di SD bertujuan untuk membentuk warga negara yang baik, yaitu warga negara yang memiliki kemampuan dan keterampilan yang berguna bagi diri dalam hidup sehari-hari dan warga negara yang bangga sebagai bangsa Indonesia dan cinta tanah air.

Menurut Sapriya (2009: 12), IPS di tingkat sekolah dasar pada dasarnya bertujuan untuk mempersiapkan para peserta didik sebagai warga negara yang menguasai pengetahuan (knowledge), keterampilan (skills), sikap dan nilai (attitudes and values) yang dapat digunakan sebagai kemampuan untuk memecahkan masalah pribadi atau masalah sosial serta kemampuan mengambil keputusan dan berpartisipasi dalam berbagai kegiatan kemasyarakatan agar menjadi warga negara yang baik. Oleh karena itu, kegiatan-kegiatan belajar dan mengajar (Permendiknas No. 22 Tahun 2006) hendaknya menjadi orientasi utama pelaksanaan Pendidikan IPS di sekolah dasar.

1. Mengenal konsep-konsep yang berkaitan dengan kehidupan masyarakat dan lingkungannya.

2. Memiliki kemampuan dasar untuk berpikir logis dan kritis, rasa ingin tahu, inkuiri, memecahkan masalah, dan ketrampilan dalam kehidupan sosial.

3. Memiliki komitmen dan kesadaran terhadap nilai-nilai sosial dan kemanusiaan.

4. Memiliki kemampuan berkomunikasi, bekerjasama dan berkompetisi dalam masyarakat yang majemuk, di tingkat lokal, nasional dan global.

Salah satu indikator tercapainya tujuan pembelajaran IPS di SD seperti yang telah dikemukakan di atas adalah hasil belajar. Hasil belajar yang tinggi pada mata pelajaran IPS mengidikasikan keberhasilan proses belajar mengajar. Namun sebaliknya apabila hasil belajar IPS rendah mengindikasikan ketidakberhasilan proses pembelajaran IPS (Maria Patrisia Wau, 2015: 15)

Berdasarkan hasil observasi dan wawancara pada guru mata pelajaran IPS kelas IV di SDI Bajawa, ditemukan bahwa hasil belajar IPS selalu rendah pada materi permasalahan sosial. Hal ini terlihat dari tidak tercapainya KKM yang seharusnya 70, tetapi selalu berada di bawah KKM tersebut. Selain itu dari hasil pengamatan, terlihat bahwa guru belum menerapkan model-model pembelajaran dalam pembelajaran IPS, padahal terdapat banyak model pembelajaran IPS yang inovatif. Berkaitan dengan hal tersebut, Agar tujuan IPS di SD seperti yang telah diuraikan di atas dapat tercapai, maka dalam membelajarkan IPS di SD guru diharapkan dapat dapat memilih model pembelajaran yang dapat memacu semangat siswa untuk secara aktif ikut terlibat dalam pengalaman belajarnya. Salah satu alternatif model pembelajaran yang memungkinkan dikembangkannya keterampilan berpikir siswa (penalaran, komunikasi, dan koneksi) dalam memecahkan masalah adalah pembelajaran berbasis masalah (Problem Based Learning) Model pembelajaran berbasis masalah dikembangkan berdasarkan konsep konsep yang dicetuskan oleh Jerome Bruner (Agus Suprijono, 2009: 68). Konsep tersebut berkaitan dengan discovery learning.

Model pembelajaran berbasis masalah merupakan model pembelajaran berdasarkan teori belajar konstruktivisme (Trianto, 20099: 92). Dalam model PBL pembelajaran dimulai dengan menyajikan permasalahan yang nyata yang membutuhkan suatu penyelesaian melalui kerja sama antar siswa. Dalam model ini peran guru membimbing siswa melewati langkah demi langkah dalam kegiatan pembelajaran, guru juga berperan dalam penggunaan strategi dan keterampilan yang dibutuhkan untuk menyelesaikan suatu masalah. Guru juga menciptakan suasana kelas yang fleksibel dan beriorientasi pada upaya penyelidikan siswa. 
Menurut Arends (2007: 42) mengenai esensi PBL berupa menyuguhkan berbagai situasi bermasalah yang autentik dan bermakna kepada siswa, yang berfungsi untuk bahan investigasi dan penyelidikan bagi siswa. Tugas siswa adalah berusaha dalam menyelidiki dan memecahkan masalah yang disugguhkan dalam proses pembelajaran. Sedangkan John Dewey (Trianto, 2009: 91) menyatakan bahwa "belajar berdasarkan masalah adalah belajar interaksi antara stimulus dengan respons, merupakan hubungan antara dua arah belajar dan lingkungan". Lingkungan dalam hal ini memberikan masukan berupa masalah dan bantuan, sedangkan sistem saraf otak berperan memberikan bantuan dalam memecahkan masalah sehingga masalah dapat dihadapi, diselidiki, dinilai, dianalisis serta dinilai pemecahanya dengan baik.

Pembelajaran berbasis masalah merupakan cara yang efektif untuk mengajarkan anak berpikir tingkat tinggi (Trianto, 2009: 92). Kemampuan berpikir tingkat tinggi mencangkup kemampuan memecahkan masalah. Pembelajaran berbasis masalah membantu siswa untuk memproses informasi yang masuk atau pengalaman yang telah dimiliki oleh siswa, untuk melakukan prosedur memecahkan masalah.

Menurut Arends (Trianto, 2009: 92), pembelajaran berbasis masalah merupakan suatu pembelajaran dimana siswa memecahkan masalah autentik dengan tujuan untuk membangun pengetahuanya sendiri, mengembangkan inkuiri dan keterampilan berpikir tinggi (memcahkan masalah), mengembangkan kemandirian dan percaya diri. Menurut Made Wena (2009: 91) pembelajaran berbasis masalah merupakan pembelajaran dengan menghadapkan siswa pada permasalahan permasalahan praktis sebagai pijakan dalam belajar. Senada dengan hal tersebut menurut Bound, Fellateti dan Fograty (Made Wena, 2009: 91) pembelajaran berbasis masalah merupakan suatu pembelajaran dengan membuat konfrontasi kepada siswa dengan masalah-masalah praktis, berbentuk open ended melalui stimulus dalam belajar.

Menurut Sovie dan Hughes (Made Wena, 2009: 91), PBL memiliki beberapa karakteristik antara lain sebagai berikut:

1. Proses pembelajaran dimulai dengan permasalahan

2. Permasalahan yang diberikan harus berhubungan dengan dunia nyata siswa

3. Mengorganisasikan pembelajaran di seputar permasalahan bukan di seputar disiplin ilmu

4. Memberikan tanggung jawab yang besar dalam membentuk dan menjalankan secara langsung proses belajar mereka sendiri menggunakan kelompok kecil

5. Menuntut siswa mempresentasikan apa yang telah dipelajarinya dalam bentuk produk dan kinerja menghasilkan produk dan memamerkanya. Karakteristik tersebut dimunculkan dalam proses pembelajaran menggunakan model PBL.

Berdasarkan uraian diatas maka rumusan masalah dalam penelitian ini adalah apakah apakah terdapat perbedaan hasil belajar IPS antara siswa yang mengikuti model pembelajaran dengan menggunakan model Problem Based Learning dengan siswa yang mengikuti model konvensional pada siswa kelas IV SDI Bajawa. sedangkan tujuan yang ingin dicapai melalui penelitian ini adalah untuk mengetahui perbedaan hasil belajar IPS antara siswa yang mengikuti model Problem Based Learning dengan siswa yang mengikuti model konvensional pada siswa kelas IV SDI Bajawa.

\section{Metode Penelitian}

Penelitian ini adalah penelitian quasi eksperimen (eksperimen semu), karena tidak semua variabel dikontrol secara ketat dan penelitian ini hanya berupa terapan dan dilakukan dalam waktu singkat. Rancangan penelitian yang digunakan dalam penelitian ini adalah "Posttest Only Control Group Design". Untuk lebih memahami rancangan ini dapat dilihat pada tabel 1 berikut ini.

\begin{tabular}{ccc}
\multicolumn{3}{c}{ Tabel 1. Rancangan Penelitian } \\
\hline $\mathbf{R}$ & $\mathbf{X}$ & $\mathbf{O}_{1}$ \\
\hline $\mathbf{R}$ & - & $\mathrm{O}_{2}$ \\
\hline & & $($ Sugiyono, 2008)
\end{tabular}

Keterangan:

(Sugiyono, 2008)

$\begin{array}{ll}\mathrm{R} & \text { : random } \\ \mathrm{X} & \text { : kelompok ekperimen } \\ \text { - } & \text { : kelompok kontrol }\end{array}$


Dalam penelitian ini terdapat 2 kelompok yang masing-masing dipilih secara random (R). Kelompok pertama diberi perlakuan $(\mathrm{X})$ dan kelompok yang lain tidak. Kelompok yang diberi perlakuan disebut kelompok eksperimen dan kelompok yang tidak diberi perlakuan disebut kelompok kontrol. Pengaruh adanya perlakuan (treatment) adalah $\left(\mathrm{O}_{1}: \mathrm{O}_{2}\right)$. Dalam penelitian yang sesungguhnya pengaruh treatment dianalisis dengan uji beda pakai statistik t-test, misalnya kalau terdapat perbedaan signifikan antara kelompok eksperimen dan kelompok kontrol, maka perlakuan yang diberikan berpengaruh secara signifikan.

Populasi dalam penelitian ini adalah SDI Bajawa. sedangkan sampel yang dipilih dalam penelitian ini adalah siswa kelas IV A dan Kelas IV B SDI Bajawa.

Distribusi sampel penelitian dapat dilihat pada tabel di bawah ini:

Tabel 2 Distribusi Sampel

\begin{tabular}{cccc}
\hline No & Kelas Populasi & Kelompok & Jumlah Kelas \\
\hline 1 & Kelas IV A & Eksperimen & 21 \\
\hline 2 & Kelas IV B & Kontrol & 20 \\
\hline \multicolumn{2}{r}{ Jumlah } & & 41 \\
\hline
\end{tabular}

Metode yang digunakan untuk pengumpulan data pada penelitian ini adalah dengan menggunakan tes. Untuk metode test menggunakan objektif test (pilihan ganda). Data yang diperoleh melalui hasil penelitian, yakni data tentang hasil belajar IPS dengan model Problem Based Learning dianalisis secara deskriptif kuantitatif yaitu: mencari harga Mean, Median, Modus dan Standar Deviasi dan Varians dari setiap variabel yang diteliti (Koyan, 2012). Setelah dianalisis secara deskriptif kuantitatif, selanjutnya dilakukan uji prasyarat analisis yang meliputi uji normalitas data dan homogenitas varians. Setelah itu dilakukan uji hipotesis

Uji normalitas sampel dilakukan untuk pengujian terhadap normal tidaknya sebaran data yang akan dianalisis. Distribusi normal sebagai alat statistik yang terpenting untuk melakukan analisis lebih lanjut dari data keadaan kelompok, sehingga dapat dianalisis perbedaan maupun hubungan serta meramalkannya. Kriteria pengujian data memiliki sebaran distribusi normal jika angka signifikan yang signifikan yang dihasilkan lebih besar dari 0,05 dan dalam hal lain data tidak berdistribusi normal. Dalam penelitian ini untuk melakukan perhitungan uji normalitas menggunakan aplikasi manual dengan menggunakan statistic Kolmogorow-Smirnow pada signifikansi 0,05. Uji ini dilakukan terhadap data postes, perubahan skor postest terhadap kelompok eksperimen dan kelompok kontrol. (Koyan, 2012: 111).

Uji homogenitas varians antar kelompok digunakan untuk mengukur apakah sebuah grup (kelompok data) mempunyai varians yang sama diantara anggota grup tersebut. Uji homogenitas varians juga dilakukan untuk menyajikan bahwa perbedaan yang terjadi pada uji hipotesis benar-benar terjadi akibat perbedaan dalam kelompok. Uji homogenitas varians ini dilakukan dengan menggunakan aplikasi SPSS 23 IBM dengan menggunakan levene statistic.

Uji hipotesis digunakan untuk menguji hipotesis yang telah dikemukakan pada penelitian, yaitu terdapat perbedaan hasil belajar IPS pada siswa yang belajar dengan menggunakan model pembelajaran kontekstual Problem Based Learning dengan siswa yang belajar menggunakan model pembelajaran konvensional. Pengujian hipotesis statistik adalah sebagai berikut.

$$
\begin{aligned}
& \mathrm{H}_{0}=\mu 1=\mu 2 \\
& \mathrm{H}_{1}=\mu 2=\mu 2
\end{aligned}
$$

Jika $t_{\text {hitung }}>\mathrm{t}_{\text {tabel }}$ maka $\mathrm{H}_{0}$ ditolak atau $\mathrm{H}_{1}$ diterima

Keterangan:

$\mathrm{H}_{0} \quad$ = tidak terdapat perbedaan hasil belajar IPS siswa yang belajar dengan menggunakan model Problem Based Learning dan siswa yang belajar dengan menggunakan model konvensional

$\mathrm{H}_{1} \quad$ = terdapat perbedaan hasil belajar IPS siswa yang belajar dengan menggunakan model Problem Based Learning dan siswa yang belajar dengan menggunakan model konvensional

$\mu 1 \quad=$ model pembelajaran Problem Based Learning

$\mu 2=$ model pembelajaran konvensional

Dalam penelitian ini untuk menguji hipotesis digunakan rumus $t$-test kelompok independen (tidak berkorelasi) dengan rumus polled varians sebagai berikut.

$$
\mathrm{t}=\frac{\bar{x} 1-\bar{x} 2}{\sqrt{\left.\frac{(n 1-1)+(n 2-2) s 2^{2}}{n 1+n 2-2}\left|\frac{1}{n 1}\right| \frac{1}{n 2}\right)}} \quad \text { Rumus (Polled Varians) }
$$


Keterangan:

$\bar{x}_{1}=$ rerata sampel 1

$\bar{x}_{2}=$ rerata sampel 2

$\mathrm{n}_{1}=$ jumlah responden sampel 1

$\mathrm{n}_{2}=$ jumlah responden sampel 2

$\mathrm{s}_{1}{ }^{2}=$ varian sampel 1

$\mathrm{s}_{2}{ }^{2}=$ varian sampel 2

Menurut Sugiyono (Koyan, 2012:41) ketentuan untuk menggunakan rumus t-tes di atas adalah sebagai berikut.

1) Jika anggota sampel $\mathrm{n}_{1}=\mathrm{n}_{2}$, dan varians homogen, dapat digunakan t-test dengan polled varians dengan derajat kebebasan $(\mathrm{db})=\left(\mathrm{n}_{1}+\mathrm{n}_{2}\right)-2$

2) Jika $\mathrm{n}_{1} \# \mathrm{n}_{2}$, varians homogen dapat digunakan t-test dengan polled varians dengan derajad kebebasan $\left(n_{1}+n_{2}\right)-2$

3) Jika $\mathrm{n}_{1} \# \mathrm{n}_{2}$ dan tidak homogen dapat digunakan salah satu rumus diatas, dengan $d b=\mathrm{n}_{1}-1$ atau $\mathrm{n}_{2}-2$ (bukan $\mathrm{n}_{1}+\mathrm{n}_{2-2}$ )

4) Jika $n_{1} \# n_{2}$ dan tidak homogen, digunakan rumus separated varians, harga $t$ pengganti $t_{\text {tabel }}$ dihitung selisih dari harga $t_{\text {tabel }}$ dengan $\mathrm{db}=\left(\mathrm{n}_{1}-1\right)$ dan $\mathrm{db}=\left(\mathrm{n}_{2}-1\right)$ dibagi dua kemudian ditambah dengan harga t yang terkecil

\section{Hasil Penelitian}

Setelah dilakukan penelitian melalui penerapan model Problem Based Learning pada kelompok eksperimen dan model konvensional pada kelompok kontrol maka diperoleh data melalui tes hasil belajar yang berkaitan dengan ruang lingkup materi yang diteliti. Berikut adalah hasil penelitian

\section{Uji prasyarat analisis \\ Uji Normalitas Data}

Uji normalitas dilakukan untuk menguji normal tidaknya sebaran data yang dianalisis. Secara statistic hipotesis tersebut dapat dirumuskan sebagai berikut.

$\mathrm{HO}: \mathrm{fO}=\mathrm{fe}$ data normal

$\mathrm{H} 1: \mathrm{f0} \neq \mathrm{fe} \quad$ data tidak normal

Uji normalitas dapat dianalisis dengan menggunakan program SPSS 23. Uji normalitas sebaran data dalam penelitian ini dilakukan dengan menggunakan statistic Kolmogorov-Smirnov.

Tabel 3. Ringkasan Hasil Uji Normalitas Data

\begin{tabular}{cccccrr}
\hline \multicolumn{8}{c}{ Kolmogorov-Smirnov $^{\mathrm{a}}$} & \multicolumn{3}{c}{ Shapiro-Wilk } \\
\hline & \multicolumn{1}{c}{ Statistic } & Df & \multicolumn{1}{c}{ Sig. } & Statistic & df & Sig. \\
\hline X1 &, 116 & 19 &, 200 &, 962 & 19 &, 611 \\
\hline X2 &, 180 & 19 &, 107 &, 931 & 19 &, 180 \\
\hline
\end{tabular}

Berdasarkan tabel 4.5 hasil uji normalitas dengan program SPSS 23 terbukti bahwa nilai signifikansi hasil belajar IPS berada di atas 0,05. Kelompok eksperimen $(X 1)=0,200$ sedangkan kelompok kontrol $(X 2)=$ 0,107 , sehingga dinyatakan bahwa semua kelompok data yang diperoleh dalam penelitian ini berdistribusi normal.

\section{Uji Homogenitas Varians}

Menguji homogenitas varians dimaksudkan untuk menunjukan bahwa hasil belajar pada sampel kelompok belajar menggunakan model Problem Based Learning dan sampel kelompok dengan model konvensional berasal dari populasi yang memiliki varian yang sama dari segi statistik. Untuk menguji homogenitas varian dapat menggunakan teknik analisis program SPSS 23. Kriteria agar varians dikatakan homogeny jika angka signifikan yang dihasilkan lebih besar ari 0,05 .

Hasil uji homogenitas varian dapat dilihat pada tabel 4 berikut: 
Tabel 4 Deskriptif Hasil Uji Homogenitas Varians Hasil Belajar IPA Test of Homogeneity of Variances

\begin{tabular}{ccccc}
\hline & Levene Statistic & df1 & df2 & Sig. \\
\hline $\mathrm{X} 1$ & 2,657 & 5 & 11 &, 082 \\
$\mathrm{X} 2$ & 22,656 & 5 & 10 &, 067 \\
\hline
\end{tabular}

Berdasarkan tabel 4 di atas, menunjukkan bahwa Levene Statistik 2,657 (X1) dengan angka signifikan 0,082 dan Levene Statistik (X2) dengan angka signifikan 0,67 ternyata lebih besar dari angka signifikansi $5 \%(\alpha=0,05)$. Dengan demikian varian hasil belajar IPS berasal dari data populasi yang homogen.

\section{Uji Hipotesis Penelitian}

Dari hasil uji asumsi statistik yaitu uji normalitas dan uji homogenitas diperoleh bahwa data dari kelompok eksperimen dan kelompok kontrol berdistribusi normal dan homogen. Berdasarkan hal tersebut maka dilanjutkan pada pengujian hipotesis tindakan atau hipotesis alternatif (H1). Dalam penelitian ini pengaruh treatment dianalisis dengan statistik t-test. Jika terdapat perbedaan yang signifikan antara kelompok eksperimen dan kelompok kontrol, maka perlakuan yang diberikan berpengaruh secara signifikan.

Dalam penelitian ini untuk menguji hipotesis digunakan t-test kelompok independent (tidak berkorelasi) polled varians. Hasil analisis diperoleh $\mathrm{t}$-hitung $=15,02$. Karena $\mathrm{n} 1 \neq \mathrm{n} 2$ dan homogen maka t-tabel dengan $\mathrm{db}=\mathrm{n} 1+\mathrm{n} 2-2=39$ dengan taraf signifikansi $5 \%(\alpha=0,05)$ adalah 2,042. Ternyata t-hitung $=15,02>\mathrm{t}-$ tabel $=2,042$, sehingga H0 ditolak dan H1 diterima. Ini berarti terdapat perbedaan yang signifikan hasil belajar IPS antara siswa yang belajar dengan menggunakan model Problem Based Learning dengan siswa yang belajar dengan menggunakan model pembelajaran konvensional. Dari rata-rata hitung diketahui bahwa rata-rata hitung kelompok Eksperimen lebih tinggi dari kelompok Kontrol $(66,40>56,9)$. Dengan demikian disimpulkan bahwa model pembelajaran kontekstual berpengaruh terhadap hasil belajar IPS.

\section{Pembahasan}

Berdasarkan hasil perhitungan uji-t diperoleh t-hitung $=15,02$. Karena $\mathrm{n} 1 \neq \mathrm{n} 2$ dan homogen maka t-tabel dengan $\mathrm{db}=\mathrm{n} 1+\mathrm{n} 2-2=39$ dengan taraf signifikansi $5 \% \quad(\alpha=0,05)$ adalah 2,042 . Ternyata $\mathrm{t}$-hitung $=15,02>\mathrm{t}$-tabel $=2,042$, sehingga H0 ditolak dan H1 diterima. Ini berarti terdapat perbedaan yang signifikan hasil belajar IPS antara siswa yang belajar dengan menggunakan model Problem Based Learning dengan siswa yang belajar dengan menggunakan model pembelajaran konvensional. Dari rata-rata hitung diketahui bahwa rata-rata hitung kelompok Eksperimen lebih tinggi dari kelompok Kontrol $(66,40>56,9)$. Dengan demikian hasil penelitian menunjukkan bahwa terdapat pengaruh hasil belajar Ilmu Pengetahuan Sosial pada siswa kelas IV SDI Bajawa dengan menggunakan model Problem Based Learning. Salah satu faktor yang dapat mempengaruhi hasil belajar IPS dalam penelitian ini adalah diterapkannya model Problem Based Learning .

\section{Simpulan}

Berdasarkan hasil penelitian ditemukan bahwa terdapat perbedaan hasil belajar IPS yang signifikan antara siswa yang menggunakan model Problem Based Learning dengan hasil belajar IPS pada siswa yang menggunakan pembelajaran konvensional. Hal ini dapat dilihat dari hasil perhitungan uji hipotesis melalui uji-t ternyata $\mathrm{H}_{0}$ ditolak dan $\mathrm{H}_{1}$ diterima (thitung =15,02 > ttabel = 2,042) dengan derajad kebebasan $(d b)=n 1+n 2-2=39$ dan taraf signifikansi 5\%. Ini berarti terdapat perbedaan yang signifikan hasil belajar IPS antara siswa yang belajar dengan menggunakan model Problem Based Learning dengan siswa yang belajar dengan menggunakan model pembelajaran konvensional. Rata-rata hasil belajar IPS kelompok eksperimen lebih besar dari rata-rata hasil belajar IPA kelompok kontrol yaitu 66,40 > 56,9. Disimpulkan bahwa model pembelajaran Problem Based Learning berpengaruh terhadap hasil belajar IPS siswa kelas IV SDI Bajawa Kecamatan Bajawa Tahun Ajaran 2016/2017. 


\section{Daftar Pustaka}

Suprijono, Agus. (2009). Cooperative Learning. Surabaya: Pustaka Pelajar.

Koyan, I Wayan. (2012). Statistik Pendidikan. Bali: Universitas Pendidikan Ganesha Press.

Wau, Maria Patrisia (2015). Pengaruh Model Pembelajaran Cooperative Learning Tipe Jigsaw Terhadap

Hasil Belajar IPS Pada Siswa Kelas IV SDI Dolumolo Tahun Pelajaran 2013/2014. Jurnal Ilmiah

Pendidikan Citra Bakti, 2(1), 13-21.

Made Wena. (2008). Strategi Pembelajaran Inovatif Kontemporer. Malang: Bumi Aksara.

Martorella, P.H. (1994). Social studies for elementary school children, developing young citizen. New York: Merill.

Sapriya. (2009). Pendidikan IPS konsep dan pembelajaran. Bandung: Remaja Rosdakarya.

Trianto. (2009). Mendesain Model Pembelajaran Inovatif Progesif. Surabaya: Kencana. (2010). Model Pembelajaran Terpadu. Surabaya: Bumi Aksara. 